\title{
Gastrointestinal effects of resistant starch, soluble maize fibre and pullulan in healthy adults
}

\author{
Abby S. Klosterbuer ${ }^{1}$, Meredith A. J. Hullar ${ }^{2}$, Fei Li $^{2}$, Elizabeth Traylor ${ }^{2}$, Johanna W. Lampe ${ }^{2}$, \\ William Thomas ${ }^{3}$ and Joanne L. Slavin ${ }^{1 *}$ \\ ${ }^{1}$ Department of Food Science and Nutrition, University of Minnesota, 1334 Eckles Avenue, St Paul, MN 55108, USA \\ ${ }^{2}$ Fred Hutchinson Cancer Research Center, 1100 Fairview Avenue North, Seattle, WA 98109, USA \\ ${ }^{3}$ Division of Biostatistics, School of Public Health, University of Minnesota, 420 Delaware Street, Southeast, Minneapolis, MN \\ 55455, USA
}

(Submitted 17July 2012 - Final revision received 2 November 2012 - Accepted 12 December 2012 - First published online 7 February 2013)

\begin{abstract}
Fibre has been shown to exert a number of benefits on gastrointestinal (GI) health, yet its intake is low. Addition of novel fibres to food products may increase fibre intake and improve gut health. The objective of the present study was to evaluate the influence of three novel fibres on GI outcomes in healthy human subjects. A total of twenty healthy participants (ten men and ten women) with normal BMI (23 (SEM 2) kg/m²) participated in the present randomised, double-blind, cross-over study with five treatment periods. Participants consumed a maltodextrin control or $20-25 \mathrm{~g} / \mathrm{d}$ fibre from soluble maize fibre (SCF) or resistant starch (RS), alone or in combination with pullulan $(\mathrm{SCF}+\mathrm{P}$ and $\mathrm{RS}+\mathrm{P})$. The treatment periods were $7 \mathrm{~d}$ with a 3-week washout between the periods. Stool samples were collected on day 7 of each period, and GI tolerance was assessed via a questionnaire on days 1 and 6 . There were no treatment differences in stool weight or consistency. SCF significantly reduced stool pH and increased total SCFA production compared with RS and control. RS + P significantly increased the percentage of butyrate compared with all the other treatments. Overall, GI symptoms were minimal. $\mathrm{SCF}+\mathrm{P}$ led to the highest GI score on day 1 , while RS $+\mathrm{P}$ had the highest score on day 6 . Both SCF treatments caused a significant shift in the gut microbial community. These functional fibres are generally well tolerated, have minimal effects on laxation and may lead to beneficial changes in SCFA production in healthy adults.
\end{abstract}

Key words: Fibre: Microbiota: Butyrate: Tolerance

Dietary fibre exerts a number of beneficial effects on gastrointestinal (GI) health, and fibre consumption is associated with a reduced risk of colorectal cancer and other forms of chronic disease ${ }^{(1)}$. Despite this, fibre intake in the USA is low, with most individuals consuming only half the recommended amounts ${ }^{(2)}$.

Many of the potential health benefits are related to fermentation of fibre by gut bacteria. Fermentation leads to the production of SCFA, the most abundant of which are acetate, propionate and butyrate. While all SCFA have metabolic significance, butyrate is considered the most important for colonic health due to its effects on promoting normal colonocyte development. Additionally, SCFA production can lower luminal $\mathrm{pH}$, which may inhibit growth of potentially pathogenic bacteria ${ }^{(3)}$. Fibre may also benefit laxation by increasing stool weight and improving stool consistency.

In recent years, the role of gut microbiota in human health has received increasing attention. While many studies have focused on the concept of prebiotics and the ability of fibre to alter levels of a few select bacterial species, there is now interest in assessing how diet influences the overall bacterial community. Terminal restriction fragment length polymorphism (TRFLP) analysis is a bacterial fingerprinting technique that provides a rapid overview of inter-individual differences in the gut microbial community (GMC). This technique has been used previously to identify changes in gut microbiota in response to dietary interventions ${ }^{(4)}$.

Although fibre has many potential health benefits, increasing fibre in the diet can also lead to undesirable side effects such as gas and bloating. These symptoms may act as a deterrent for fibre intake. Tolerance is defined as a state in which there is an absence of unwanted symptoms related to fibre consumption $^{(5)}$. It is of interest to identify fibres that can be added to food products without causing intolerance in order to increase overall fibre consumption.

Abbreviations: GCRC, General Clinical Research Center; GI, gastrointestinal; GMC, gut microbial community; P, pullulan; RS, resistant starch; SCF, soluble maize fibre; TRFLP, terminal restriction fragment length polymorphism.

*Corresponding author: J. L. Slavin, fax +1 612625 5272, email jslavin@umn.edu 
While many Americans could benefit from increasing the amount of fibre in their diets, it is important to consider the type of fibre in order to balance tolerance and physiological benefits.

Functional fibres are constantly being developed by the food industry for use as ingredients in food products. However, little research is available regarding the effects of novel functional fibres on GI health. Resistant starch (RS), soluble maize fibre (SCF) and pullulan (P) are maize-based fibres that can easily be incorporated into foods or beverages. Previous studies have shown that these fibres are well fermented $^{(6)}$, but research regarding their physiological effects in vivo is limited. Therefore, the objective of the present study was to examine the influence of these fibres on laxation, GI tolerance, SCFA production and the GMC in healthy human subjects.

\section{Experimental methods}

\section{Participants}

A total of twenty participants (ten men and ten women) were recruited via flyers posted around the University of Minnesota campus. Participants were initially screened over the phone to determine eligibility for the study. Eligible participants were English-speaking, healthy men and women between 18 and 60 years of age, non-smoking, not taking medications, weight stable and had a BMI between 18.5 and $27 \mathrm{~kg} / \mathrm{m}^{2}$. Participants were excluded if they had a history of cardiovascular, renal or hepatic disease, diabetes mellitus, GI conditions affecting digestion and absorption, were vegetarians or consumed more than approximately $15 \mathrm{~g}$ of fibre per $\mathrm{d}$. Participants were not taking fibre supplements or laxatives and had not taken antibiotics for at least 6 months before the study. The present study was conducted according to the guidelines laid down in the Declaration of Helsinki, and all procedures involving human subjects were approved by the University of Minnesota Institutional Review Board Human Subjects Committee. Written informed consent was obtained from all subjects before any study procedures.

\section{Study design}

Before official enrolment, participants attended a screening visit at the University of Minnesota General Clinical Research Center (GCRC) to obtain informed consent, collect anthropometric measurements, verify medical history and receive study instructions and supplies. Eligible participants were instructed to follow a low-fibre $(\leq 15 \mathrm{~g})$, lead-in diet and to avoid fibre supplements, excessive exercise and alcohol for $24 \mathrm{~h}$ before the study visits. Participants were required to maintain their current activity level and were instructed not to initiate a weight-loss programme for the duration of the study. Before any dietary intervention, participants collected a baseline faecal sample while following their habitual diet. Baseline faecal samples were analysed using the same protocol as samples collected following intervention periods.

Participants consumed five treatments in a double-blind, cross-over design with treatment periods of $7 \mathrm{~d}$ followed by a $21 \mathrm{~d}$ washout period. On day 1 of the study, following a $12 \mathrm{~h}$ fast, participants arrived at the GCRC and consumed either a low-fibre control breakfast or one of four fibrecontaining breakfasts. Meals consisted of a muffin, hot cereal, and fruit-flavoured beverage. For the next $6 \mathrm{~d}$, participants consumed the study products at home. Treatments were provided as cereal bars and a beverage mix, which was pre-measured into $500 \mathrm{ml}$ water bottles. Participants were instructed to consume four cereal bars and one beverage over the course of each day.

The test breakfast on day 1 supplied $25 \mathrm{~g}$ SCF or RS alone or in combination with $5 \mathrm{~g}$ pullulan $(\mathrm{SCF}+\mathrm{P}$ and $\mathrm{RS}+\mathrm{P})$. The cereal bars and beverage contained the same fibre treatments, but at a slightly lower dose of $20 \mathrm{~g}$ supplemental fibre per d. All test products were provided by Tate and Lyle, Inc. The study products were matched for macronutrient and energy content, and were consumed along with the participants' habitual diets. The compositions of the control and fibre treatments are displayed in Table 1.

SCF is produced via hydrolysis of maize starch, followed by cooling to form a branched structure. It has an average degree of polymerisation of 10 . The RS used in the present study is

Table 1. Composition of the test meals ${ }^{\star}$

\begin{tabular}{|c|c|c|c|c|c|}
\hline & \multicolumn{5}{|c|}{ Treatments } \\
\hline & Control & SCF & $\mathrm{SCF}+\mathrm{P}$ & RS & $\mathrm{RS}+\mathrm{P}$ \\
\hline \multicolumn{6}{|l|}{ Test breakfast (day 1)† } \\
\hline Fibre $(g)$ & $2 \cdot 8$ & $27 \cdot 8$ & $27 \cdot 8$ & $27 \cdot 2$ & $27 \cdot 2$ \\
\hline Fat $(\mathrm{g})$ & $12 \cdot 7$ & $12 \cdot 6$ & $12 \cdot 6$ & $12 \cdot 8$ & $12 \cdot 8$ \\
\hline Protein (g) & $10 \cdot 4$ & $10 \cdot 3$ & $10 \cdot 3$ & $10 \cdot 3$ & $10 \cdot 3$ \\
\hline Energy (kJ) & 2474 & 2582 & 2569 & 2466 & 2453 \\
\hline Available carbohydrate (g) & 104.9 & 103.9 & $103 \cdot 7$ & $105 \cdot 8$ & $105 \cdot 7$ \\
\hline Water (g) & $372 \cdot 1$ & $347 \cdot 8$ & $347 \cdot 9$ & 349.5 & $349 \cdot 7$ \\
\hline \multicolumn{6}{|c|}{ Cereal bars and beverage (days $2-7$ ) $\ddagger$} \\
\hline Fibre (g) & 3.84 & $23 \cdot 8$ & $23 \cdot 8$ & $22 \cdot 3$ & $22 \cdot 3$ \\
\hline Energy (kJ) & 2687 & 2799 & 2799 & 2676 & 2675 \\
\hline Available carbohydrate (g) & $135 \cdot 2$ & $135 \cdot 2$ & $135 \cdot 2$ & $133 \cdot 7$ & $133 \cdot 7$ \\
\hline
\end{tabular}

SCF, soluble maize fibre; $P$, pullulan; RS, resistant starch.

${ }^{*}$ All data provided by Tate and Lyle, Inc.

† Values are the sum of the entire meal: $90 \mathrm{~g}$ muffin, $170 \mathrm{~g}$ hot cereal mix, $110 \mathrm{~g}$ whole milk and $240 \mathrm{ml}$ beverage.

$\ddagger$ Values are the sum of the study products for each day: $4.40 \mathrm{~g}$ cereal bars and $500 \mathrm{ml}$ beverage. 
classified as type 3 RS (RS3, retrograded starch) produced from heat moisture-treated, high-amylose maize starch. Pullulan is a linear glucose homopolysaccharide formed via the fermentation of dextrin by the yeast Aureobasidium pullulans. Resistance to degradation by human digestive enzymes is due to the presence of $\alpha-1,6$ bonds, as well as to steric hindrance which limits access to $\alpha-1,4$ linkages $^{(7)}$. The control treatment was fully digestible maltodextrin. Treatment materials were analysed as dietary fibre by AOAC method 991.43 or AOAC method 2001.03. Dietary fibre analyses were provided by Tate and Lyle, Inc.

\section{Stool records and tolerance}

Before leaving the GCRC, participants were given instructions on completing a GI symptom questionnaire at 20.00 hours on days 1 and 6 of each study period. Subjects were instructed to consume all test products for the day before completing the questionnaire. The symptom questionnaire assessed stool frequency and consistency, as well as GI side effects. Symptoms included flatulence, bloating, abdominal cramps and stomach noises, and were rated on a ten-point scale, where $1=$ none and $10=$ excessive. Stool consistency was assessed on a scale of $1-4$, where $1=$ liquid and $4=$ hard. Participants completed a daily record of study product consumption and were asked to return any uneaten study products to assess compliance. Participants were also instructed on the collection and delivery of a faecal sample on day 7 of each treatment period. Participants collected one fresh stool sample using the Commode Specimen Collection Kit (Sage Products) and sample collection bags provided by the study staff. Participants delivered samples to the GCRC on ice within $2 \mathrm{~h}$ of defecation.

\section{Stool sample collection and bacteria DNA extraction}

Immediately following the delivery of stool samples by participants, study staff collected two pea-sized samples of fresh faeces and added them to a tube containing $5 \mathrm{ml}$ RNAlater (Ambion). The collection tube was inverted fifteen times, and samples were stored at $-80^{\circ} \mathrm{C}$. Frozen samples were shipped to the Fred Hutchinson Cancer Research Center for analysis. Faecal samples in RNAlater were homogenised using an OMNI tissue homogeniser (OMNI, Inc.) and aliquoted into $300 \mu \mathrm{l}$ volumes. Faecal bacterial genomic DNA was extracted in duplicate using a QIAamp stool mini kit (Qiagen) with 1 min bead beating ${ }^{(8)}$.

\section{Faecal chemistry and SCFA}

Stool wet weight was determined in $\mathrm{g}$ by weighing the filled collection bag on a balance and subtracting the average bag weight. Stool consistency was determined subjectively by investigators and rated using King's Stool Chart ${ }^{(9)}$. Faecal samples were homogenised with a hand blender and $\mathrm{pH}$ was determined in an aliquot using a glass electrode at $25^{\circ} \mathrm{C}$ (Orion PerpHecT LogR Meter, model 350; Thermo Electron Corporation).

Acetate, propionate, butyrate and total SCFA were extracted in duplicate and concentrations were determined via GC using the method described by Schneider et al. ${ }^{(10)}$, with minor modifications. Briefly, $200 \mathrm{mg}$ of stool were suspended in $1.6 \mathrm{ml}$ distilled water. Then, $2 \mathrm{ml}$ diethyl either and $0.4 \mathrm{ml}$ sulphuric acid ( $50 \%$ ) were added, along with $2 \mu$ l ethyl butyrate as the internal standard. Samples were mixed in an orbital shaker for $45 \mathrm{~min}$ and centrifuged at $3000 \mathrm{rpm}$ for $5 \mathrm{~min}$. The supernatant was transferred to a glass test-tube and residual water was absorbed using calcium chloride. Samples were filtered using a $1 \mathrm{ml}$ syringe (Sherwood Medical) and a Fisherbrand nylon filter ( $13 \mathrm{~mm}$, pore diameter $0.2 \mathrm{~mm}$; Fisher Scientific), and frozen at $-80{ }^{\circ} \mathrm{C}$ until analysis via GC. Analysis was conducted using a Stabilwax DA column $(30 \mathrm{~m}, 0.52 \mathrm{~mm}$ internal diameter, $1 \mu \mathrm{m}$ film thickness; Restek) with He as the carrier gas.

\section{Terminal restriction fragment length polymorphism}

A TRFLP profile was generated for each extracted faecal bacterial genomic DNA sample using a protocol described previously, with minor modification ${ }^{(8)}$. Bacterial $16 \mathrm{~S}$ ribosomal RNA genes were amplified with primers 11-27f and 519r (GWATTACCGCGGCGCTG). The forward primer is identical to 8 -27f as described by $\mathrm{Li}$ et $a{ }^{(8)}{ }^{(8)}$ except that the initial $5^{\prime}$-AGA nucleotides were removed in order to reduce specificity and capture more GMC organisms ${ }^{(11)}$.

\section{Data analysis}

SCFA concentrations, stool weight, stool pH, stool frequency and GI symptoms were compared among the treatments using a mixed-effects linear model with a random subject effect (Proc Mixed) using Statistical Analysis Systems statistical software package version 9.3 (SAS Institute). Carry-over and period $\times$ treatment interaction terms were tested in each model, but were excluded from the final models since they were not significant. Paired $t$ tests were used to determine differences in GI symptoms between days 1 and 6. Data are presented as means with their standard errors, adjusted for study visit. Statistical significance was set at $P<0 \cdot 05$.

TRFLP profiles were analysed with DAx software (Van Mierlo Software Consultancy) as described previously ${ }^{(4)}$. Non-metric multidimensional scaling ordination analysis was performed on the mean of duplicate $P_{\mathrm{i}}$ values using PC-ORD (MJM Software Design) ${ }^{(12)}$. Permutational multivariate ANOVA was used to test whether there was an effect of treatment on the composition of the GMC. All $P$ values were corrected for multiple comparisons using Bonferroni adjustments where borderline significance was at $P=0 \cdot 1$ / $15=0.007$ and significance at $P=0.05 / 15=0.0033$

To identify organisms (represented by TRFLP fragment length) that occurred uniquely in participants on different treatments, we performed indicator species analysis in PC-ORD (MJM Software Design). We linked the TRFLP fragment lengths of the indicator peaks with gut microbial taxonomic annotations. Our reference database consisted of archived human GMC sequences from the comprehensive SILVA 102 reference database of curated high-quality 16S ribosomal RNA gene sequences ${ }^{(13)}$ and approximately 30000 sequences generated from ten individuals. We generated 
Table 2. Stool pH, weight, number, consistency and SCFA concentrations of healthy adults consuming soluble maize fibre (SCF, $20 \mathrm{~g} / \mathrm{d}$ ) or resistant starch (RS, $20 \mathrm{~g} / \mathrm{d}$ ) alone or in combination with $5 \mathrm{~g}$ pullulan $(\mathrm{SCF}+\mathrm{P}$ and $\mathrm{RS}+\mathrm{P})$ or no supplemental fibre (maltodextrin control) after 6-7d of treatment

(Mean values with their standard errors)

\begin{tabular}{|c|c|c|c|c|c|c|}
\hline & \multicolumn{6}{|c|}{ Treatments } \\
\hline & Control & SCF & $\mathrm{SCF}+\mathrm{P}$ & RS & $R S+P$ & SEM \\
\hline Stool $\mathrm{pH}$ & $6 \cdot 70^{\mathrm{a}}$ & $6.47^{\mathrm{b}}$ & $6 \cdot 54^{\mathrm{a}, \mathrm{b}}$ & $6 \cdot 70^{\mathrm{a}}$ & $6 \cdot 59^{\mathrm{a}, \mathrm{b}}$ & 0.1 \\
\hline Stool weight $(\mathrm{g})$ & $100 \cdot 1$ & $94 \cdot 3$ & $102 \cdot 0$ & $119 \cdot 0$ & $109 \cdot 6$ & 14 \\
\hline Number of stools (self-reported) & $1 \cdot 15^{\mathrm{b}}$ & $1 \cdot 15^{\mathrm{b}}$ & $1 \cdot 37^{\mathrm{a}, \mathrm{b}}$ & $1.71^{\mathrm{a}}$ & $1.65^{\mathrm{a}}$ & 0.2 \\
\hline Stool consistency (self-reported) ${ }^{\star}$ & 2.08 & $2 \cdot 33$ & $2 \cdot 32$ & $2 \cdot 13$ & $2 \cdot 27$ & 0.2 \\
\hline Stool consistency (investigator-reported) $†$ & $2 \cdot 00$ & $2 \cdot 20$ & $2 \cdot 10$ & $2 \cdot 15$ & $2 \cdot 35$ & 0.2 \\
\hline Total SCFA ( $\mu \mathrm{mol} / \mathrm{g}$ stool) & $31 \cdot 2^{\mathrm{b}}$ & $35 \cdot 5^{\mathrm{a}}$ & $32 \cdot 9^{a, b}$ & $31 \cdot 1^{\mathrm{b}}$ & $33 \cdot 7^{\mathrm{a}, \mathrm{b}}$ & 1.7 \\
\hline \multicolumn{7}{|l|}{ SCFA ratio ( $\%$ of total SCFA) } \\
\hline Acetate & $38.9^{\mathrm{b}}$ & $40 \cdot 7^{\mathrm{a}}$ & $40 \cdot 6^{\mathrm{a}}$ & $41 \cdot 3^{\mathrm{a}}$ & $38.5^{\mathrm{b}}$ & 0.9 \\
\hline Propionate & $29 \cdot 6^{\mathrm{a}}$ & $29 \cdot 1^{\mathrm{a}}$ & $28 \cdot 6^{\mathrm{a}}$ & $25 \cdot 6^{\mathrm{b}}$ & $25 \cdot 5^{\mathrm{b}}$ & 0.9 \\
\hline Butyrate & $31 \cdot 6^{\mathrm{b}, \mathrm{c}}$ & $30 \cdot 2^{c}$ & $30 \cdot 9^{c}$ & $33.1^{\mathrm{b}}$ & $36.0^{\mathrm{a}}$ & 0.9 \\
\hline
\end{tabular}

${ }_{\mathrm{a}, \mathrm{b}, \mathrm{c}}$ Mean values within a row with unlike superscript letters were significantly different $(P<0.05)$.

${ }^{*}$ Self-reported stool consistency on day 6 was rated on a four-point scale $(1=$ hard, $4=$ diarrhoea).

† Investigator-reported stool consistency was rated on a four-point scale $(1=$ hard and formed; $2=$ soft and formed; $3=$ loose and unformed; $4=$ liquid $\left.^{(9)}\right)$.

in silico terminal restriction fragments from each of the 67506 reference sequences using the $A l u$ I and $R s a$ I restriction endonuclease cut sites. Terminal restriction fragment sequences with lengths (bp) matching the two Rsa TRFLP indicator peaks (309 and $314 \mathrm{bp}) \pm 2 \mathrm{bp}$ were collected.

\section{Results \\ Participants}

All the twenty participants who enrolled in the study completed all the five treatments. Mean age and BMI were 29 (SEM 8) years and $23($ SEM 2$) \mathrm{kg} / \mathrm{m}^{2}$, respectively.

\section{Stool characteristics}

Stool characteristics are presented in Table 2. Stool weight and stool consistency (investigator-reported and subject-reported) did not differ among the treatments. The self-reported number of stools was greater on day 6 following the RS and $\mathrm{RS}+\mathrm{P}$ treatments compared with the control $(P=0.0119)$ and SCF $(P=0.0257)$ treatments. Stool pH was significantly lower when participants consumed the SCF treatment compared with the control $(P=0.0472)$ and RS $(P=0.0457)$ treatments, while $\mathrm{pH}$ values for the $\mathrm{SCF}+\mathrm{P}$ and $\mathrm{RS}+\mathrm{P}$ treatments were intermediate. These $\mathrm{pH}$ differences were reflected in SCFA concentrations. Total SCFA were significantly higher for the SCF treatment compared with the RS $(P=0.005)$ and control $(P=0.007)$ treatments, but did not differ from the SCF $+\mathrm{P}$ or $\mathrm{RS}+\mathrm{P}$ treatment. The percentage of acetate was higher for the SCF $(P=0.02), \mathrm{SCF}+\mathrm{P}(P=0.03)$ and RS $(P=0.002)$ treatments compared with the control treatment. Both RS treatments resulted in a lower percentage of propionate compared with the control and SCF treatments $(P<0 \cdot 0001)$. The percentage of butyrate was significantly higher than all the other treatments following the consumption of RS $+\mathrm{P}(P<0 \cdot 001)$, and was higher than both SCF treatments following the consumption of RS $(P<0 \cdot 01)$.

\section{Gastrointestinal symptoms}

GI symptom ratings are reported in Table 3. On day 1, participants reported greater bloating following the consumption of the $\mathrm{RS}+\mathrm{P}$ treatment compared with the control $(P=0.0263)$ and SCF $(P=0.0157)$ treatments. Flatulence was highest when participants consumed the SCF $+\mathrm{P}$ treatment compared with the control $(P=0.0271)$ and SCF $(P=0.0111)$ treatments, while the two RS treatments were intermediate. Abdominal cramps and stomach noise did not differ. The GI score for the SCF $+\mathrm{P}$ treatment was significantly greater than that for the SCF and control treatments. On day 6 , the RS $+\mathrm{P}$ treatment caused greater bloating than the RS $(P=0 \cdot 0045)$, SCF $(P=0.0105)$ and control treatments $(P=0.0045)$; greater flatulence than the SCF $(P=0.0452)$ and control $(P=0.0023)$ treatments; and greater abdominal cramps and stomach noise than all the other treatments. The GI score for the RS $+\mathrm{P}$ treatment was significantly greater than that for all the other treatments. When GI symptoms were statistically different between days 1 and 6, symptoms were always rated lower on day 6 (Table 3).

\section{Gut microbial community}

Non-metric multidimensional scaling analysis explained 81 and $86 \%$ of the total variation in the composition of the GMC using Alu I and Rsa I, respectively. In Fig. 1, SCF and $\mathrm{SCF}+\mathrm{P}$ tend to cluster at the bottom of the cloud of samples. Permutational multivariate ANOVA showed that there was a significant effect of treatment on the GMC measured using $R s a$ I $(P<0.0006)$ but none using Alu I $(P>0.05)$. The GMC associated with baseline was significantly different from the SCF $(P<0.001)$ and SCF $+\mathrm{P}(P<0.001)$ treatments. Among the treatments, the control was significantly different from the SCF $(P<0.001)$ and SCF $+\mathrm{P}(P<0.0002)$ treatments. The SCF treatment was significantly different from the RS treatment $(P<0 \cdot 007)$, and the SCF $+\mathrm{P}$ treatment was significantly different from the $\mathrm{RS}+\mathrm{P}$ treatment $(P<0 \cdot 002)$. The GMC following the consumption of the SCF and SCF $+\mathrm{P}$ treatments was not 
Table 3. Gastrointestinal (Gl) tolerance ratings after consuming the test treatment on days 1 and 6 of each treatment period

(Mean values with their standard errors)

\begin{tabular}{|c|c|c|c|c|c|c|}
\hline & \multicolumn{6}{|c|}{ Treatments } \\
\hline & Control & SCF & $\mathrm{SCF}+\mathrm{P}$ & RS & $\mathrm{RS}+\mathrm{P}$ & SEM \\
\hline \multicolumn{7}{|l|}{ Bloating } \\
\hline Day 1 & $2 \cdot 40^{\mathrm{b}, \mathrm{c}}$ & $2 \cdot 30^{c}$ & $3 \cdot 30^{a, b}$ & $3 \cdot 10^{\mathrm{a}, \mathrm{b}, \mathrm{c}}$ & $3.50^{\mathrm{a}}$ & 0.54 \\
\hline Day 6 & $2 \cdot 45^{\mathrm{b}}$ & $2 \cdot 60^{b}$ & $3 \cdot 11^{a, b}$ & $2 \cdot 45^{\mathrm{b}}$ & $3.89^{a}$ & 0.52 \\
\hline \multicolumn{7}{|c|}{ Flatulence } \\
\hline Day 1 & $3 \cdot 10^{b, c}$ & $2 \cdot 90^{\mathrm{c}}$ & $4 \cdot 39^{\mathrm{a}}$ & $4 \cdot 10^{a, b}$ & $4 \cdot 00^{a, b, c}$ & 0.49 \\
\hline Day 6 & $2 \cdot 25^{\mathrm{c} *}$ & $2 \cdot 75^{b, c}$ & $3 \cdot 09^{\mathrm{a}, \mathrm{b}, \mathrm{c} *}$ & $3 \cdot 40^{\mathrm{a}, \mathrm{b}}$ & $3 \cdot 66^{\mathrm{a}}$ & 0.38 \\
\hline \multicolumn{7}{|c|}{ Abdominal cramps } \\
\hline Day 1 & $2 \cdot 10$ & $1 \cdot 85$ & 2.42 & $2 \cdot 00$ & $2 \cdot 68$ & 0.49 \\
\hline Day 6 & $1 \cdot 35^{\mathrm{b} *}$ & $1 \cdot 75^{b}$ & $1 \cdot 61^{b}$ & $1.65^{b}$ & $2 \cdot 89^{a}$ & 0.42 \\
\hline \multicolumn{7}{|c|}{ Stomach noise } \\
\hline Day 1 & 3.00 & $2 \cdot 40$ & $3 \cdot 30$ & $2 \cdot 60$ & 2.76 & 0.45 \\
\hline Day 6 & $1.90^{\mathrm{b}}$ & $1 \cdot 80^{\mathrm{b}}$ & $2 \cdot 06^{\mathrm{b} *}$ & $2.05^{b}$ & $2.94^{a}$ & 0.33 \\
\hline \multicolumn{7}{|c|}{ Gl score‡ } \\
\hline Day 1 & $2 \cdot 65^{b, c}$ & $2 \cdot 36^{c}$ & $3 \cdot 35^{\mathrm{a}}$ & $3 \cdot 00^{a, b, c}$ & $3 \cdot 24^{a, b}$ & 0.38 \\
\hline Day 6 & $1.99^{\mathrm{b} *}$ & $2 \cdot 23^{b}$ & $2 \cdot 47^{\mathrm{b} *}$ & $2 \cdot 39^{b}$ & $3 \cdot 35^{\mathrm{a}}$ & 0.33 \\
\hline
\end{tabular}

significantly different from one another. The indicator species analysis showed that Rsa I peak 309 was significantly enriched after the SCF treatment $(P<0.0006)$ and Rsa I peak 314 was significantly enriched after the SCF $+\mathrm{P}$ treatment $(P<0 \cdot 0014)$. Rsa I peak 309 was identified as either Anaerococcus vaginalis or Parabacteroides goldsteinii and Rsa I peak 314 was identified as either Parabacteroides distasonis or Parabacteroides merdae using an in silico TRFLP prediction program based on $16 \mathrm{~S}$ ribosomal RNA sequences from the SILVA database and human reference samples.

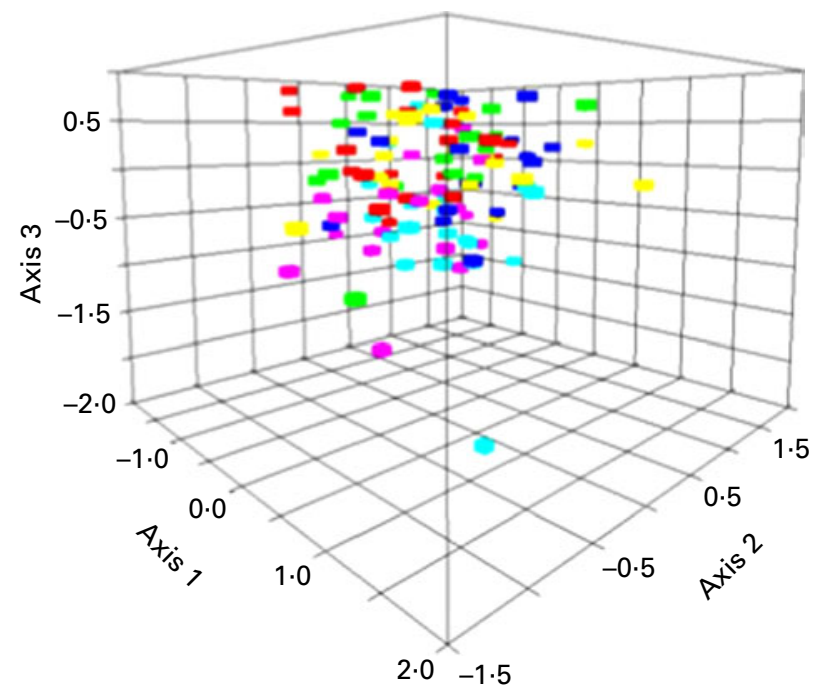

Fig. 1. Non-metric multidimensional scaling analysis of $R s a$ I terminal restriction fragment length polymorphism patterns of the 16S ribosomal RNA gene from the gut microbial community of the study participants on the different dietary interventions. Red, control; green, soluble maize fibre (SCF); light blue, SCF + pullulan (P); fuchsia, resistant starch (RS); dark blue, RS + P; yellow, baseline. (A colour version of this figure can be found online at journals.cambridge.org/bjn).

\section{Discussion}

Despite the relatively high dose of fibre provided in the present study, few changes in stool characteristics were observed. The reduction in stool $\mathrm{pH}$ following the consumption of SCF was minor ( 0.23 units), but was consistent with an earlier study in which participants consumed $21 \mathrm{~g} \mathrm{SCF} / \mathrm{d}$ for 3 weeks ${ }^{(14)}$. Walker et al. ${ }^{(15)}$ reported that a one-unit shift in $\mathrm{pH}$ had marked effects on bacterial populations and SCFA production in vitro. However, the clinical significance of smaller changes in $\mathrm{pH}$ has not been well studied. In contrast to the present study, Stewart et al. ${ }^{(16)}$ found no differences in $\mathrm{pH}$ when participants consumed $12 \mathrm{~g} \mathrm{SCF} / \mathrm{d}$, suggesting that a higher dose may be needed for an effect. Most studies have reported a minimal effect of $\mathrm{RS}$ on $\mathrm{pH}^{(16-21)}$.

Fibre can increase stool weight via the physical presence of the fibre, the water held by the fibre and increased bacterial mass from fermentation of the fibre ${ }^{(22)}$. In the present study, the supplemental fibres had no effect on stool weight. In contrast, RS has been reported to increase stool wet weight by $0 \cdot 7-2.7 \mathrm{~g} / \mathrm{g}$ RS consumed, using doses from 25 to $55 \mathrm{~g} / \mathrm{d}^{(21-24)}$. Likewise, $21 \mathrm{~g} \mathrm{SCF} / \mathrm{d}$ was shown to increase faecal dry weight by $0.9 \mathrm{~g} / \mathrm{g} \mathrm{fed}^{(14)}$. However, these studies looked at stool weight over $3-5 \mathrm{~d}$ periods. In the present study, stool weight was determined from a single sample, so it is possible that any effect on laxation may have been missed due to the short collection period.

Normal stool frequency ranges from three times per $d$ to three times per week ${ }^{(25)}$. The RS treatments led to a minor increase ( 0.56 stools $)$ in the number of stools on day 6. Most studies have reported no effect of RS on stool frequency in healthy participants when measured over the course of a week or longer ${ }^{(17,18,23)}$. Timm et al. ${ }^{(26)}$ reported an increase by 0.9 stools over a $5 \mathrm{~d}$ period for participants consuming 
$20 \mathrm{~g} \mathrm{SCF} / \mathrm{d}$. However, no laxative effect of SCF was found in the present study. Again, the present study is limited by the fact that stool frequency was only assessed for $1 \mathrm{~d}$. In addition, the present study was conducted in healthy individuals with normal bowel function. Fibre tends to have a normalising effect on bowel frequency, after which only stool weight increases $^{(20)}$. Thus, it is likely that we would have seen a greater effect in constipated individuals.

SCFA are a marker of fermentation and are considered important for colonic health. We observed a significant increase in total SCFA following the consumption of SCF. Previous studies have also reported higher faecal SCFA concentrations with the consumption of SCF compared with the control, although these differences did not reach significance $^{(14,16)}$. Changes in total SCFA concentrations mirrored differences in $\mathrm{pH}$ among the treatments, suggesting that these acids are a major contributor to colonic $\mathrm{pH}$. The increased percentage of butyrate following the consumption of RS in the present study is consistent with other reports both in vitro and in vivo ${ }^{(22,24,27)}$. Given the growing evidence for a protective role of butyrate in colonic health, this suggests that addition of RS to food products may be beneficial.

GI tolerance is an important issue when considering fibres for addition to food products, as it may have an effect on the acceptability of the product by the consumer. Mean symptom scores for all the treatments were low $(1 \cdot 6-4 \cdot 4)$, indicating that the fibres were well tolerated overall. The SCF treatment appeared to be the best tolerated, and did not differ from the control for any of the measurements. Previous studies have also found SCF to be well tolerated, with only minor increases in GI symptoms compared with the control ${ }^{(14,16)}$. RS was also well tolerated and only differed from the control for flatulence on day 6 . This is consistent with other research reporting increased flatulence with $\mathrm{RS}$ at doses ranging from 10 to $39 \mathrm{~g} / \mathrm{d}^{(16,19,22)}$.

Although SCF and RS were well tolerated alone, addition of pullulan led to an increase in most GI symptoms. Previous studies have also reported increased symptom ratings following the consumption of $12-50 \mathrm{~g}$ pullulan ${ }^{(16,28,29)}$. The present study used only $5 \mathrm{~g}$ pullulan, indicating that minor increases in GI symptoms are observed even at low levels. In vitro studies have found that pullulan is rapidly fermented and increases gas production ${ }^{(6,30)}$. If pullulan is also rapidly fermented in vivo, this may explain the observed increase in symptoms, since gas is perceived more in the proximal bowel $^{(31)}$. In contrast, RS and SCF were more slowly fermented in vitro ${ }^{(6)}$, which may lead to improved tolerance.

GI symptoms tended to be lower on day 6 than on day 1 . This may be related to distributing the fibre over the course of the day, rather than consuming the fibre in a single dose. This would reduce the amount of substrate available for fermentation and subsequent gas production. Research with sugar alcohols, another form of low digestible carbohydrate, has shown that ingestion of several divided doses is better tolerated than a single dose of the same amount ${ }^{5,32)}$. The reduction in GI symptoms from days 1 to 6 may also be related to chronic ingestion of the same fibre source. Okubo et al. ${ }^{(33)}$ found that flatulence was reported at the beginning of the experiment but gradually declined within the first week of participants consuming partially hydrolysed guar gum. Others have reported habituation and adaptation of GI symptoms when fibre was consumed over a period of several weeks ${ }^{(34)}$.

The present analyses showed that there was a significant change in the GMC with the dietary interventions. We used two fingerprinting approaches, Alu I-TRFLP, which focuses on the phylum Firmicutes, and Rsa I-TRFLP, which encompasses the phylum Bacteroidetes ${ }^{(35)}$. However, the changes with dietary enrichment were only associated with Rsa I-TRFLP. In particular, the relative abundance of TRFLP peaks, putatively associated as members of the Parabacteroides genus, increased in abundance when participants consumed SCF and SCF + P. These organisms are non-butyrate-producing bacteria that have previously been associated with a RS enrichment ${ }^{(19)}$. Hooda et al. ${ }^{(36)}$ also reported a shift in the microbiota following the consumption of $21 \mathrm{~g} \mathrm{SCF} / \mathrm{d}$ for 3 weeks, although differences in the Parabacteroides genus were not observed. This may be due to a shorter length of intervention in the present study.

In contrast to previous research ${ }^{(19)}$, the RS treatments did not cause an increase in Parabacteroides in the present study. This may be explained by the type of RS used. In the study by Martinez et al $^{(19)}$, type 4 RS (chemically modified starch) increased $P$. distasonis, whereas type 2 RS (granular starch) had no effect; type 3 RS, which was used in the present study, was not evaluated. Walker et al. ${ }^{(37)}$ reported an increase in Ruminococcus bromii and Eubacterium rectale when overweight participants consumed type 3 RS. This was not observed in the present study, and may be due to differences in the microbiota between lean and overweight individuals. These studies have suggested that the effects of fibre on the GMC cannot be generalised, even within a specific class of fibre. While the present study provided an initial screening of the effect of fibre intervention on the GMC, future studies could include a more thorough characterisation of the GMC by sequencing $16 \mathrm{~S}$ ribosomal RNA genes.

In conclusion, consumption of relatively large doses $(20-25 \mathrm{~g} / \mathrm{d})$ of RS and SCF was well tolerated and had minimal effects on laxation. Further research using a longer period of bowel habit evaluation in individuals with constipation may help identify potential laxation benefits of these fibres. SCF increased total SCFA production, while RS improved the ratio of butyrate, suggesting that fermentation of these fibres may have beneficial effects in the colon. Additional research is needed to further explore the effects of these fibres on gut microbiota and possible implications for human health.

\section{Acknowledgements}

The present study was supported by Tate and Lyle Health and Nutrition Sciences. A. S. K. conducted the study, analysed the samples and wrote the manuscript. M. A. J. H., E. T., F. L. and J. W. L. designed and conducted the microbiota analysis. W. T. coordinated the statistical design and completed the data analysis. J. L. S. obtained funding for the study and supervised the efforts for the study. All authors reviewed and approved the manuscript. The authors have no conflicts of interest to declare. 


\section{References}

1. Aune D, Chan DSM, Lau R, et al. (2011) Dietary fibre, whole grains, and risk of colorectal cancer: systematic review and dose-response meta-analysis of prospective studies. Br Med J 343, d6617.

2. Food and Nutrition Board, Institute of Medicine (2005) Dietary Reference Intakes for Energy, Carbohydrates, Fiber, Fat, Fatty Acids, Cholesterol, Protein, and Amino Acids. Washington, DC: National Academies Press.

3. Topping DL \& Clifton PM (2001) Short-chain fatty acids and human colonic function: roles of resistant starch and nonstarch polysaccharides. Physiol Rev 81, 1031-1064.

4. Li F, Hullar MAJ, Schwarz Y, et al. (2009) Human gut bacterial communities are altered by addition of cruciferous vegetables to a controlled fruit- and vegetable-free diet. $J$ Nutr 139, 1685-1691.

5. Livesey G (2001) Tolerance of low-digestible carbohydrates: a general view. Br J Nutr 85, Suppl. 1, S7-S16.

6. Maathuis A, Hoffman A, Evans A, et al. (2009) The effect of the undigested fraction of maize products on the activity and composition of the microbiota determined in a dynamic in vitro model of the human proximal large intestine. $J \mathrm{Am}$ Coll Nutr 28, 657-666.

7. Kendall CW, Esfahani A, Hoffman AJ, et al. (2008) Effect of novel maize-based dietary fibers on postprandial glycemia and insulinemia. J Am Coll Nutr 27, 711-718.

8. Li F, Hullar MA \& Lampe JW (2007) Optimization of terminal restriction fragment polymorphism (TRFLP) analysis of human gut microbiota. J Microbiol Methods 68, 303-311.

9. Whelan K, Judd PA \& Taylor MA (2004) Assessment of fecal output in patients receiving enteral tube feeding: validation of a novel chart. Eur J Clin Nutr 58, 1030-1037.

10. Schneider SM, Girard-Pipau F, Anty R, et al. (2006) Effects of total enteral nutrition supplemented with a multi-fibre mix on faecal short-chain fatty acids and microbiota. Clin Nutr 25, 82-90

11. Weisburg WG, Barns SM, Pelletier DA, et al. (1991) 16S ribosomal DNA amplification for phylogenetic study. J Bacteriol 173, 697-703.

12. McCune B \& Grace JB (2002) Analysis of Ecological Communities, 1st ed. Glendenen Beach, OR: MjM Software.

13. Pruesse E, Quast C, Knittel K, et al. (2007) SILVA: a comprehensive online resource for quality checked and aligned ribosomal RNA sequence data compatible with ARB. Nucleic Acids Res 35, 7188-7196.

14. Boler BMV, Serao MCR, Bauer L, et al. (2011) Digestive physiological outcomes related to polydextrose and soluble maize fibre consumption by healthy adult men. Br J Nutr 106, 1864-1871.

15. Walker A, Duncan S, McWilliam Leitch EC, et al. (2005) pH and peptide supply can radically alter bacterial populations and short-chain fatty acid ratios within microbial communities from the human colon. Appl Environ Microbiol 71, 3692-3700.

16. Stewart ML, Nikhanj SD, Timm DA, et al. (2010) Evaluation of the effect of four fibers on laxation, gastrointestinal tolerance and serum markers in healthy humans. Ann Nutr Metab 56, 91-98.

17. van Munster IP, Tangerman A \& Nagengast FM (1994) Effect of resistant starch on colonic fermentation, bile acid metabolism, and mucosal proliferation. Dig Dis Sci 39, $834-842$.

18. Tomlin J \& Read NW (1990) The effect of resistant starch on colon function in humans. Br J Nutr 64, 589-595.
19. Martinez I, Kim J, Duffy P, et al. (2010) Resistant starches types 2 and 4 have differential effects on the composition of the fecal microbiota in human subjects. PLOS ONE $\mathbf{5}$, e15046.

20. Slavin JL (2008) Position of the American Dietetic Association: health implications of dietary fiber. $J$ Am Diet Assoc 108, 1716-1731.

21. Cummings JH, Beatty ER, Kingman SM, et al. (1996) Digestion and physiological properties of resistant starch in the human large bowel. Br J Nutr 75, 733-747.

22. Phillips J, Muir JG, Birkett A, et al. (1995) Effect of resistant starch on fecal bulk and fermentation-dependent events in humans. Am J Clin Nutr 62, 121-130.

23. Maki K, Sanders L, Reeves M, et al. (2009) Beneficial effects of resistant starch on laxation in healthy adults. Int J Food Sci Nutr 60, Suppl. 4, 296-305.

24. Jenkins DJ, Vuksan V, Kendall CW, et al. (1998) Physiological effects of resistant starches on fecal bulk, short chain fatty acids, blood lipids and glycemic index. J Am Coll Nutr 17, 609-616.

25. Chen LY, Ho KY \& Phua KH (2000) Normal bowel habits and prevalence of functional bowel disorders in Singaporean adults - findings from a community based study in Bishan. Community Medicine GI Study Group. Singapore Med J 41, 255-258.

26. Timm DA, Thomas W, Sanders LM, et al. (2011) Polydextrose and soluble corn fiber significantly increase stool weight, but do not influence whole gut transit time in healthy adults. FASEB J 25, 587.3.

27. McOrist A, Miller R, Bird A, et al. (2011) Fecal butyrate levels vary widely among individuals but are usually increased by a diet high in resistant starch. J Nutr 141, 883-889.

28. Spears JK, Karr-Lilienthal LK, Grieshop CM, et al. (2005) Glycemic, insulinemic, and breath hydrogen responses to pullulan in healthy humans. Nutr Res 25, 1029.

29. Wolf BW, Garleb KA, Choe YS, et al. (2003) Pullulan is a slowly digested carbohydrate in humans. J Nutr $\mathbf{1 3 3}$, 1051-1055.

30. Spears JK, Karr-Lilienthal LK, Bauer LL, et al. (2007) In vitro fermentation characteristics of selected glucose-based polymers by canine and human fecal bacteria. Arch Anim Nutr 61, 61-73.

31. Harder H, Serra J, Azpiroz F, et al. (2003) Intestinal gas distribution determines abdominal symptoms. Gut 52, $1708-1713$.

32. Tetzloff W, Dauchy F, Medimagh S, et al. (1996) Tolerance to subchronic, high-dose ingestion of erythritol in human volunteers. Regul Toxicol Pharmacol 24, S286-S295.

33. Okubo T, Ishihara N, Takahashi H, et al. (1994) Effects of partially hydrolyzed guar gum intake on human intestinal microflora and its metabolism. Biosci Biotechnol Biochem 58, 1364-1369

34. Pasman W, Wils D, Saniez MH, et al. (2006) Long-term gastrointestinal tolerance of NUTRIOSE FB in healthy men. Eur J Clin Nutr 60, 1024-1034.

35. Karlsson F, Ussery D, Nielsen J, et al. (2011) A closer look at bacteroides: phylogenetic relationship and genomic implications of a life in the human gut. Microb Ecol $\mathbf{6 1}$, 473-485.

36. Hooda S, Boler BMV, Serao MCR, et al. (2012) 454 pyrosequencing reveals a shift in fecal microbiota of healthy adult men consuming polydextrose or soluble corn fiber. J Nutr 142, 1259-1265.

37. Walker A, Ince J, Duncan S, et al. (2011) Dominant and diet-responsive groups of bacteria within the human colonic microbiota. ISME J 5, 220-230. 